\title{
Pembelajaran Luas Permukaan Prisma Menggunakan Konteks Packaging
}

\author{
Afifah Hanun ${ }^{1}$, Rully Charitas Indra Prahmana ${ }^{2 *}$ \\ ${ }^{1}$ Universitas Ahmad Dahlan, Jl. Ringroad Selatan, Bantul, DIY 5519, afifahhanun97@gmail.com \\ ${ }^{2}$ Universitas Ahmad Dahlan, Jl. Ringroad Selatan, Bantul, DIY 5519, rully.indra@mpmat.uad.ac.id*
}

\begin{abstract}
ABSTRAK
Pemahaman konsep sangat diperlukan dalam pembelajaran matematika, sehingga diperlukan suatu konteks untuk mempermudah siswa dalam memahami konsep matematis. Penggunaan konteks merupakan salah satu karakteristik dalam pembelajaran matematika dengan Pendekatan Matematika Realistik Indonesia (PMRI). Tujuan penelitian ini adalah untuk mengetahui peran konteks packaging dalam memberikan pemahaman konsep luas permukaan prisma dan mengetahui hasil belajar siswa dalam pembelajaran luas permukaan prisma melalui pendekatan PMRI. Penelitian ini dilaksanakan dengan menggunakan metode design research. Subjek penelitian ini adalah seluruh siswa kelas VIII D SMP N 5 Banguntapan Bantul Yogyakarta. Objek penelitian ini adalah pengenalan konsep luas permukaan prisma. Teknik pengumpulan data menggunakan dokumentasi, rekaman video, data tertulis, dan observasi. Selanjutnya, teknik analisis data dalam penelitian ini menggunakan analisis data, validitas, dan reliabilitas. Hasil penelitian menunjukkan bahwa konteks packaging dapat digunakan sebagai starting point dalam pembelajaran luas permukaan prisma. Selain itu, hasil belajar siswa setelah mengikuti pembelajaran luas permukaan prisma menggunakan konteks packaging mendapatkan nilai rata-rata sebesar 93 dengan frekuensi ketuntasan 96,15\%.
\end{abstract}

Kata Kunci: Pendidikan Matematika Realistik Indonesia, Luas Permukaan Prisma, Design Research, Packaging.

\begin{abstract}
Conceptual understanding is essential for learning mathematics, so the use of context is essential to facilitate students in understanding mathematical concepts. The use of context is one of the characteristics of Indonesian Realistic Mathematics Approach (PMRI). The study aims to both determine the role of packaging context in providing an understanding of the prism surface area concept and assess student learning outcomes in the learning of the surface area of the prism through the PMRI approach. This research was conducted using the design research method. The subjects of this study were all eighth-grade students of SMP N 5 Banguntapan, Bantul, Yogyakarta. The object of this research is the introduction of the concept of the surface area of the prism - data collection techniques using documentation, video recording, written data, and observation. Furthermore, data analysis techniques in this study use data analysis, validity, and reliability. The results showed that the context of packaging could be used as a starting point in learning the surface area of prisms. Also, student learning outcomes after being given treatment showed that the average value obtained by students was 93 with a frequency of $96.15 \%$ completeness.
\end{abstract}


Keywords: Indonesian Realistic Mathematics Education, Prism Surface Area, Design Research, Packaging.

\section{Pendahuluan}

Kecenderungan menghafal rumus dan menerapkannya dalam pembelajaran matematika untuk menyelesaikan soal dirasa kurang menguntungkan siswa, dikarenakan siswa akan mengalami kesulitan dalam menyelesaikan permasalahan yang diberikan apabila lupa rumus [1]. Kemampuan pemahaman konsep menjadi salah satu tujuan penting dalam pembelajaran, disebabkan dengan memahami konsep yang diajarkan kepada siswa, bukan hanya sebagai hafalan, dapat membuat siswa menjadi lebih mengerti dan dapat menyelesaikan berbagai permasalahan yang ada, walau terkadang lupa akan rumusnya [2]. Selain itu, Herawati, Siroj, dan Basir [3] menjelaskan bahwa konsepkonsep dalam matematika memiliki keterkaitan antara satu dengan yang lainnya, sehingga siswa harus memahami materi matematika secara komprehensif. Namun, pada kenyataanya banyak siswa yang kesulitan dalam memahami konsep matematika sehingga, mereka tidak mampu mendefinisikan kembali materi matematika dengan bahasa mereka sendiri [4]. Oleh karena itu, pemahaman konsep sangat diperlukan dalam pembelajaran matematika.

Dalam pembelajaran matematika, pengenalan masalah yang sesuai dengan situasi nyata sebagai pengantar materi memiliki dampak positif pada pembelajaran matematika [5-8]. Banyak masalah yang dapat diangkat dari berbagai situasi (konteks), sehingga menjadi sumber belajar siswa [9-11]. Dengan menggunakan konteks akan mempermudah siswa dalam membayangkan sesuatu yang abstrak menjadi konkret.

Penggunaan konteks merupakan salah satu karakteristik dalam pembelajaran matematika dengan Pendekatan Matematika Realistik Indonesia atau disingkat PMRI [12-14]. PMRI merupakan suatu adaptasi pendekatan pembelajaran matematika dari suatu pendekatan pembelajaran di Belanda dengan nama Realistic Mathematics Education (RME) yang telah diselaraskan dengan kondisi budaya, geografi, dan kehidupan masyarakat di Indonesia [15-17]. Dalam pelaksanaanya, PMRI memberikan permasalahan nyata yang dapat ditemui oleh siswa agar siswa mampu membayangkan serta memahami masalah yang ada [18-20]. Oleh karena itu, peneliti menggunakan PMRI sebagai pendekatan yang digunakan untuk menyampaikan pembelajaran ke siswa.

Geometri merupakan bidang kajian dalam matematika yang diajarkan di SMP [21]. Materi geometri mempunyai peluang yang lebih besar untuk dipahami siswa daripada materi matematika lainnya, dikarenakan siswa mampu melihat implementasi dari belajar geometri dalam kehidupan sehari-hari [22]. Namun, kebanyakan siswa tidak menyukai materi geometri, salah satunya adalah materi bangun ruang, dikarenakan materi bangun ruang memiliki tingkat kesukaran dan keabstrakan yang tinggi $[1,22]$. Oleh karena itu, diperlukan suatu inovasi pembelajaran pada materi geometri ruang agar mudah dipahami siswa.

Sehubungan dengan hal ini, peneliti tertarik untuk mendesain pembelajaran pada materi luas permukaan prisma dengan pendekatan PMRI. Selain itu, peneliti ingin mengetahui pengaruh penerapan pendekatan PMRI terhadap pemahaman konsep matematika pada materi luas permukaan prisma. Selanjutnya, hasil penelitian ini juga diharapkan dapat dimanfaatkan oleh peneliti lain untuk meneliti lebih mendalam tentang desain pembelajaran luas permukaan prisma menggunakan pendekatan PMRI. 


\section{Metode Penelitian}

Penelitian ini menggunakan metode penelitian design research. Design research adalah metode penelitian yang dapat digunakan untuk mengembangkan solusi permasalahan dalam dunia pendidikan maupun untuk memvalidasi tentang teori pembelajaran [23]. Prahmana [23] menyatakan bahwa terdapat 3 langkah dalam pelaksanaan design research, yaitu Preliminary Design (Desain Pendahuluan), Design Experiment (Desain Percobaan), dan Retrospective Analysis (Analisis Restrospektif). Pada tahapan pertama, peneliti melakukan kajian literatur mengenai penelitian yang relevan dan teori-teori yang mendukung terkait pembelajaran luas permukaan prisma menggunakan konteks packaging. Hasil kajian pada tahap pertama ini berupa desain kegiatan pembelajaran untuk mencapai tujuan pembelajaran atau dapat disebut sebagai hipotesis lintasan belajar (Hypothetical Learning Trajectory atau HLT). Selanjutnya, pada tahapan desain percobaan, peneliti menggunakan HLT yang telah dibuat sebagai panduan selama kegiatan pembelajaran di kelas. Terakhir, pada tahapan analisis retrospektif, peneliti menganalisis sejumlah data penelitian yang telah diperoleh selama tahapan desain percobaan dengan HLT sebagai dasar pembandingnya, untuk menjawab rumusan masalah yang diajukan.

Teknik pengumpulan data yang digunakan pada penelitian ini berupa dokumentasi, rekaman video, data tertulis, dan observasi yang dikumpulkan kemudian dianalisis untuk memperbaiki HLT yang telah dirancang. Data yang diperoleh dianalisis secara restrospektif, yaitu dengan membandingkan HLT yang telah didesain dengan aktivitas pembelajaran pada fase percobaan desain agar dapat melihat sejauh mana HLT yang didesain sesuai dengan aktivitas pada fase percobaan desain. Kemudian, uji reliabilitas dan validasi oleh ahli materi.

\section{Hasil dan Pembahasan}

Pada tahapan ini, peneliti mengimplementasikan ide awal tentang penggunaan konteks packaging dalam pembelajaran luas permukaan prisma. Penelitian dilaksanakan di SMP N 5 Banguntapan Bantul Yogyakarta tahun pelajaran 2019/2020 pada semester genap. Dengan subyek penelitian siswa kelas VIII D yang berjumlah 31 siswa yang terdiri dari 14 siswa perempuan dan 17 siswa laki-laki, serta guru kelas sebagai guru model selama proses implementasi desain. Pemilihan guru kelas sebagai model diharapkan dapat memberikan pengalaman tersendiri kepada guru dalam mengimplementasikan desain yang telah dirancang dan diharapkan setelah selesai penelitian, guru yang bersangkutan dapat terus mengimplementasikan dan mungkin akan mengembangkan desain pembelajaran yang telah diimplementasikan. Tabel 1 menjelaskan jadwal pelaksanaan kegiatan pembelajaran.

Tabel 1. Jadwal Pelaksanaan Kegiatan Pembelajaran

\begin{tabular}{cccl}
\hline Pertemuan & Kegiatan Siswa & Hari, Tanggal & \multicolumn{2}{c}{ Materi } \\
\hline I & LAS 1 & Jum'at, 22 Maret 2019 & $\begin{array}{l}\text { Bentuk dan sifat bangun } \\
\text { prisma }\end{array}$ \\
II & LAS 2 & Selasa, 26 Maret 2019 & $\begin{array}{l}\text { Konsep luas permukaan } \\
\text { prisma }\end{array}$ \\
III & $\begin{array}{c}\text { LAS 3 dan Tes } \\
\text { Tertulis }\end{array}$ & Jum'at, 29 Maret 2019 & $\begin{array}{l}\text { Konsep luas permukaan } \\
\text { prisma }\end{array}$ \\
\hline
\end{tabular}

Aktivitas pembelajaran dalam penelitian ini berbasis matematika realistik $[18,20]$, yang diawal pembelajaran, guru meminta siswa untuk menyebutkan contoh bangun 
prisma yang dapat ditemukan di dalam lingkungan sekolah seperti atap sekolah, conblok, dan tenda pramuka. Selanjutnya, guru membentuk kelompok kecil yang beranggotakan 4 orang. Kemudian guru membagikan Lembar Aktivitas Siswa dan kemasan produk untuk bahan diskusi kelompok. Kemasan produk yang diberikan adalah kemasan jam tangan yang berbentuk prisma segitiga dan prisma segiempat.

Kegiatan pertama, siswa diminta mengamati kemasan produk sesuai dengan kelompoknya, dan menggambarkan sketsa kemasan produk dan memberi nama bangun. Hasilnya, beberapa siswa masih tampak bingung menentukan garis putus-putus. Hal ini disebabkan pemahaman awal siswa terkait geometri dimensi tiga masih belum baik [22] Sejumlah contoh jawaban siswa dapat dilihat pada Gambar 1.

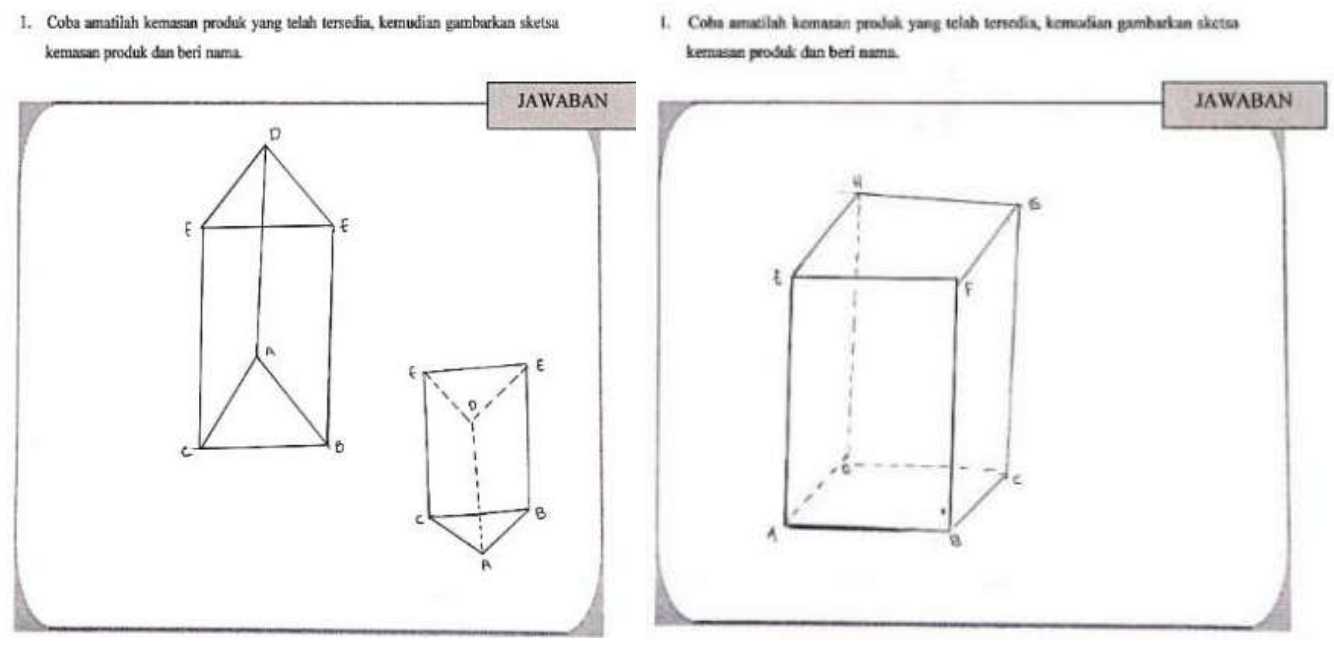

Gambar 1. Hasil Diskusi Siswa Membuat Sketsa Bangun

Kegiatan selanjutnya adalah siswa diminta membuat jaring-jaring kemasan produk sesuai dengan kelompoknya. Guru memberikan arahan kepada siswa untuk melihat kemasan produk yang telah didapatkan kelompoknya. Dalam mengerjakan soal, terdapat siswa yang kebingungan memberikan ukuran jaring-jaring, kemudian siswa bertanya kepada guru, seperti tampak pada Dialog 1.

\section{Dialog 1:}

Siswa : Pak, ini ukuranya gimana?

Guru : Ukurannya bebas, tetapi ukurannya betul.

Siswa : Oh, ya Pak.

Guru : Jadi nanti kalau dipasangkan, andaikan ini dipotong-potong jika dirangkai akan membentuk sebuah prisma.

Siswa : Ya Pak.

Setelah penjelasan tersebut, guru memberikan soal terkait jaring-jaring sebuah prisma. Hasil pekerjaan siswa menunjukkan bahwa siswa mampu membuat jaring-jaring prisma dengan aktivitas memotong dan merangkai bagian dari bahan yang diberikan. Aktivitas ini memberikan berbagai jenis prisma dengan ukuran yang berbeda-beda, namun setiap ukuran mengarah pada satu bentuk prisma yang proporsional. Ini artinya ukuran prisma harus memiliki aturan tertentu, sehingga mampu membentuk jaring-jaring prisma yang proporsional [24], sebagaimana hasil diskusi jawaban siswa dalam membuat jaring-jaring prisma tersebut, seperti tampak pada Gambar 2. 


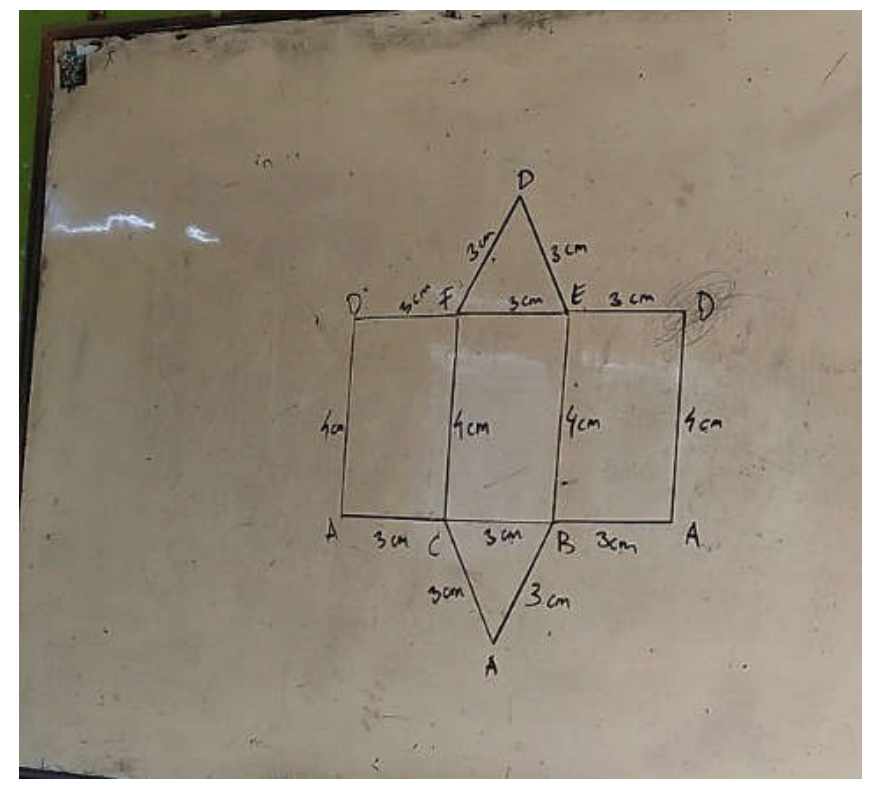

Gambar 2. Hasil Diskusi Siswa Membuat Jaring-jaring

Aktivitas selanjutnya, bertujuan menemukan dan memahami konsep luas permukaan prisma menggunakan kemasan produk yaitu dengan menguraikan kemasan produk sehingga terlihat bagian berupa bangun datar sederhana pembentuk kemasan/ prisma. Siswa diminta untuk mensketsakan jaring-jaring prisma yang ukurannya sesuai dengan kemasan produk, tetapi menggunakan ukuran skala. Terdapat siswa yang mengalami kebingungan ketika mensketsakan bangun datar pembentuk kemasan/ prisma, sebagaimana terlihat pada Dialog 2.

Dialog 2:

Siswa 1 : Pak ukuran nya gimana? Nggak muat.

Guru : Ukuran nya diskala

Siswa 2 : Skala ki piye to? Radong aku. (Sambil menyerahkan LAS ke temannya) [Skala itu gimana? Saya tidak paham. (Sambil menyerahkan LAS ke temannya)]

Guru : Skala itu misalnya 6 dibagi 2 boleh. Ukuran nya dibagi 2 itu maksudnya ukuran skala, tetapi keterangan ukurannya tetap.

Siswa 2 : Gini bukan pak? (sambil menunjukkan jawabannya)

Guru $: 6,8$, 5. Iyaaa benar.

Dalam mengerjakan soal LAS, siswa tidak hanya berdiskusi dengan kelompoknya. Namun, melakukan diskusi juga dengan kelompok lainnya. Pada dialog 4 tampak diskusi antara kelompok 2 dan kelompok 3, karena anggota kelompok 2 merasa kebingungan dalam mengerjakannya, seperti penjelasan pada Dialog 3 .

Dialog 3:

Siswa 1 (Kel 2) : Ndelok garapane kelompokmu. [Lihat pekerjaan kelompokmu]. Siswa 2 (Kel 3) : Lha nggonmu ki opo? Lak bedo to. [Kelompok mu apa? Kan beda] Siswa 3 (Kel 3) : Podo, prisma. [Sama, prisma] 
Siswa 2 (Kel 3) : Lhayo prismane ki bedo, iki prisma segitiga gonmu prisma segiempat. [Ya kan prismanya beda, ini prisma segitiga kelompokmu prisma segiempat].

Siswa 4 (Kel 3) : Kene-kene ndelok kemasanmu. [Sini lihat kemasanmu].

Siswa 1 (Kel 2) : (melempar kemasan produk ke arah kelompok 3$)$.

Siswa 4 (Kel 3): Iki lho, kene ki 5 terus kene ukurane 8. [Ini lho, sini ukurannya 5 terus sini ukurannya 8]

Siswa 3 (Kel 2): Owalah kene (Sambil meminta kemasannya). [Ohhh... Sini] (Sambil meminta kemasannya).

Siswa 4 (Kel 3) : Nyohhhh.... (Sambil melempar kemasan ke arah kelompok 2). [Nihhh....(Sambil melempar kemasan ke arah kelompok 2].

Selanjutnya, guru meminta kelompok 3 untuk menuliskan jawaban dipapan tulis. Hasil dari jawaban kelompok 3 benar, begitu juga dengan kelompok yang lain. Hal ini menandakan bahwa siswa sudah paham dalam mensketsakan jaring-jaring bangun prisma. Soal selanjutnya adalah menghitung luas permukaan bangun prisma dengan menjumlahkan terlebih dahulu luas bangun datar pembentuknya. Namun, terdapat siswa yang masih kebingungan dalam mengerjakan soal, seperti penjelasan dalam Dialog 4.

Dialog 4:

Siswa : Pak Kasihan saya mau tanya.

Guru : (Guru berjalan menghampiri siswa)

Siswa : Sini to Pak. Luas permukaan prisma itu berarti alasnya to Pak. Nah bener to luas permukaan prisma itu alas (sambil melihat ke arah kelompoknya).

Guru : Luas permukaan prisma terdiri dari ...... kalau ini bentuk apa ini? (sambil menunjuk kearah kemasan produk)

Siswa : Persegi panjang

Guru : Jadinya 4 persegi panjang sebagai sisi tegak dan persegi panjang sebagai alas tutup.

Siswa : Oh gitu to Pak. [Oh gitu ya Pak].

Kemudian, Guru meminta siswa untuk menguraikan jaring-jaringnya dan menghitung luas permukaan prisma. Pada saat diskusi kelompok, guru berkeliling kelas untuk melihat hasil pekerjaan siswa. Beberapa siswa masih tampak kebingungan dalam mencari luas permukaan prisma. Kemudian, guru menjelaskan kepada siswa untuk mencari masing-masing luas bangun datar terlebih dahulu. Selanjutnya, guru menjelaskan untuk mencari luas permukaan prisma dengan menjumlahkan semua luas bangun. Selain itu, terdapat juga siswa yang kebingungan menentukan ukurannya, seperti yang tampak pada Dialog 5.

Dialog 5:

Siswa : Pak angkanya menggunakan yang 8 itu atau skalanya?

Guru : Pakai yang 8 sesuai dengan ukuran nya.

Siswa : Ya Pak.

Setelah siswa menemukan luas permukaan prisma dari menjumlahkan semua luas bangun datarnya, guru meminta perwakilan kelompok untuk menuliskan jawaban di papan tulis. Kemudian, guru membimbing siswa untuk menemukan rumus luas permukaan prisma melalui perhitungan luas permukaan prisma tersebut. Sehingga, di dapatkan rumus luas permukaan prisma $\mathrm{L}=(2 \mathrm{x}$ luas alas $)+$ (keliling alas $\mathrm{x}$ tinggi $)$ [22] 
Proses penemuan rumus luas permukaan prisma ini merupakan hasil akhir setelah sejumlah aktivitas yang menggunakan konteks packaging sebagai starting point pembelajaran. Untuk lebih jelasnya bisa dilihat pada Gambar 3.

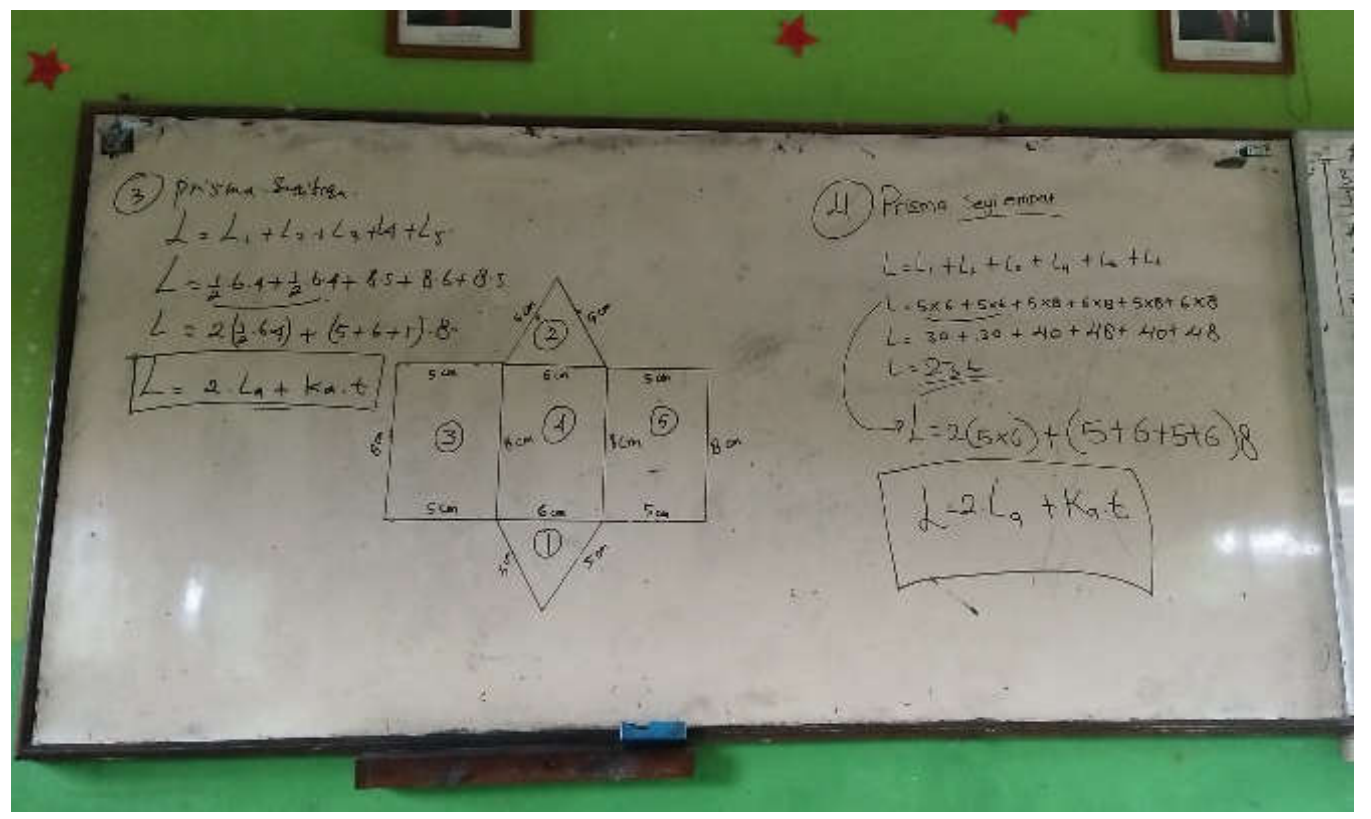

Gambar 3. Proses Mencari Rumus Luas Permukaan Prisma

Untuk mengevaluasi pemahaman siswa, guru memberikan latihan soal yang berkaitan dengan luas permukaan prisma. Hasilnya, tampak siswa mampu menerapkan konsep dasar luas permukaan prisma dibuktikan dengan cara yang digunakan untuk menyelesaikan soal berbeda namun hasil yang diperoleh benar. Hanya saja, siswa kurang teliti dalam perhitungan.

Berdasarkan hasil penelitian, pembelajaran luas permukaan prisma melalui pendekatan PMRI merupakan suatu hal baru bagi siswa. Sehingga, selama kegiatan pembelajaran pada pertemuan 1 dan 2 siswa masih beradaptasi, sehingga beberapa masih kurang teliti dalam membaca perintah. Sedangkan, pada pertemuan ketiga siswa sudah lebih baik dalam memahami LAS sehingga dapat mengerjakannya dengan baik.

Dari seluruh aktivitas di atas, dapat dilihat bahwa konteks packaging dapat digunakan siswa untuk memunculkan pemahaman siswa akan konsep dasar luas permukaan prisma di kelas VIII D SMP N 5 Banguntapan. Dengan kata lain, konteks ini sangat berguna sebagai starting point dalam pembelajaran luas permukaan prisma, yang dimulai dari kemampuan siswa dalam menyusun jarring-jaring prisma yang bersesuaian dan berlanjut pada penemuan rumus luas permukaan prisma. Hasil ini menambah bukti empiris terkait penggunaan konteks yang mampu memberikan pemahaman siswa dalam mempelajari matematika $[2,5,6,8-11,13,14]$.

Selain data proses pembelajaran, data hasil tes tertulis siswa juga sangat penting untuk mengetahui bagaimana implementasi desain pembelajaran luas permukaan prisma yang telah dirancang. Hasil tes tertulis menunjukkan bahwa masih terdapat siswa yang belum sempurna dalam mengerjakan soal-soal tes. Kesalahan-kesalahan siswa dalam mengerjakan soal-soal tes tertulis disebabkan oleh kurang teliti dalam perhitungan [22]. Selain itu, siswa kurang memahami aturan penjumlahan maupun perkalian yang menggunakan bentuk akar [24, 25]. Kesalahan lainnya juga disebabkan oleh penulisan 
siswa yang kurang jelas, sehingga siswa bingung sendiri dan mengakibatkan salah hitung, karena yang seharusnya perkalian menjadi penjumlahan $[10,13]$. Namun secara umum, siswa sudah memahami konsep luas permukaan bangun prisma.

Data hasil tes tertulis siswa setelah diberikan treatment menunjukkan bahwa ratarata hasil nilai siswa 93. Untuk KKM matematika kelas VIII SMP N 5 Banguntapan adalah 70. Selanjutnya, frekuensi ketuntasan sebesar $96,15 \%$ atau sebanyak 25 siswa, dengan 13 siswa mendapatkan nilai 100 .

\section{Simpulan}

Pembelajaran luas permukaan prisma menggunakan konteks packaging, dapat memunculkan pemahaman siswa terhadap konsep dasar luas permukaan prisma. Selain itu, pada saat pembelajaran luas permukaan prisma siswa diajak menemukan rumus untuk mencari luas permukaan prisma. Sehingga, konteks packaging berguna sebagai starting point dalam pembelajaran luas permukaan prisma, yang dimulai dari kemampuan siswa dalam menyusun jarring-jaring prisma yang bersesuaian berlanjut pada penemuan rumus luas permukaan prisma. Hasil belajar siswa setelah mengikuti kegiatan belajar mengajar berdasarkan desain pembelajaran luas permukaan prisma melalui pendekatan PMRI, menunjukkan bahwa nilai rata-rata yang diperoleh siswa adalah 93 dengan frekuensi ketuntasan 96,15\% atau sebanyak 25 siswa siswa yang nilainya diatas Kriteria Ketuntasan Minimum (KKM). Selain itu, yang mendapat nilai 100 pada tes tertulis tersebut sebanyak 13 anak, dan nilai terendah adalah 53.

\section{$5 \quad$ Daftar Pustaka}

[1] Widyawati, S. (2016). Pengaruh Kemampuan Koneksi Matematis Siswa terhadap Prestasi Belajar Matematika Ditinjau dari Gaya Belajar pada Materi Bangun Ruang Sisi Datar Siswa Kelas IX SMP di Kota Metro. Jurnal Iqra': Kajian Ilmu Pendidikan, 1(1), 47-68.

[2] Sutisna, A. P., Maulana, M., \& Subarjah, H. (2016). Meningkatkan Pemahaman Matematis Melalui Pendekatan Tematik dengan RME. Jurnal Pena Ilmiah, 1(1), $31-40$.

[3] Herawati, O. D. P., Siroj, R. A., \& Basir, M. D. (2010). Pengaruh pembelajaran problem posing terhadap kemampuan pemahaman konsep matematika siswa kelas XI IPA Sma Negeri 6 Palembang. Jurnal Pendidikan Matematika, 4(1), 70-80.

[4] Murizal, A., Yarman, \& Yerizon. (2012). Pemahaman Konsep Matematis dan Model Pembelajaran Quantum Teaching. Jurnal Pendidikan Matematika, 1(1), 1923.

[5] Simanulang, J. (2013). Pengembangan Bahan Ajar Materi Himpunan Konteks Laskar Pelangi dengan Pendekatan Pendidikan Matematika Realistik Indonesia (PMRI) kelas VII Sekolah Menengah Pertama. Jurnal Pendidikan Matematika, 7(2), 25-36.

[6] Prahmana, R. C. I., Zulkardi, Z., \& Hartono, Y. (2012). Learning Multiplication using Indonesian Traditional Game in Third Grade. Journal on Mathematics Education, 3(2), 115-132.

[7] Tanujaya, B., Prahmana, R. C. I, \& Mumu, J. (2017). Mathematics Instruction, Problems, Challenges, and Opportunities: A Case Study in Manokwari Regency, 
Indonesia. World Transactions on Engineering and Technology Education, 15(3), 287-291.

[8] Ginting, M. S., Prahmana, R. C. I., Isa, M., \& Murni, M. (2018). Improving the Reasoning Ability of Elementary School Student through the Indonesian Realistic Mathematics Education. Journal on Mathematics Education, 9(1), 41-54.

[9] Muchlis, E. E. (2012). Pengaruh Pendekatan Pendidikan Matematika Realistik Indonesia (PMRI) terhadap Perkembangan Kemampuan Pemecahan Masalah Siswa Kelas II SD Kartika 1.10 Padang. EXACTA, 10(2), 136-139.

[10] Prahmana, R. C. I. (2017). Designing Mathematics Learning Trajectory: An Introduction. LAP LAMBERT Academic Publishing.

[11] Nurdiansyah, \& Prahmana, R. C. I. (2017). Pembelajaran Keliling Lingkaran menggunakan Konteks Gelas. Jurnal Riset Pendidikan Matematika, 4(2), 128-140.

[12] Utari, R.S., Putri, R.I.I., \& Hartono, Y. (2015). Konteks Kebudayaan Palembang untuk Mendukung Kemampuan Bernalar Siswa SMP pada Materi Perbandingan. Jurnal Didaktik Matematika, 2(2), 27-37.

[13] Prahmana, R. C. I. (2012). Pendesainan Pembelajaran Operasi Bilangan Menggunakan Permainan Tradisional Tepuk Bergambar Untuk Siswa Kelas III Sekolah Dasar (SD). Unpublished Thesis. Palembang: Magister Pendidikan Matematika Universitas Sriwijaya.

[14] Yunisha, R., Prahmana, R. C. I., \& Sukmawati, K. I. (2016). Pengaruh Pendekatan Pendidikan Matematika Realistik Terhadap Kemampuan Komunikasi Matematis Siswa Kelas VII SMP. Jurnal Elemen, 2(2), 136-145.

[15] Soedjadi, R. (2014). Inti Dasar-Dasar Pendidikan Matematika Realistik Indonesia. Jurnal Pendidikan Matematika, 1(2), 1-10.

[16] Sembiring, R. K., Hoogland, K., \& Dolk, M. L. A. M. (Eds.). (2010). A Decade of PMRI in Indonesia. Bandung: PMRI Institute.

[17] Sembiring, R. K. (2014). Pendidikan Matematika Realistik Indonesia (PMRI): Perkembangan dan Tantangannya. Journal on Mathematics Education, 1(1), 11-16.

[18] Wijaya, A. (2012). Pendidikan Matematika Realistik: Suatu Alternatif Pendekatan Pembelajaran Matematika. Yogyakarta: Graha Ilmu.

[19] Idris, I., \& Silalahi, D. K. (2016). Penerapan Pendekatan Pendidikan Matematika Realistik Indonesia (PMRI) untuk Meningkatkan Kemampuan Penyelesaian Soal Cerita pada Kelas VII A SMP UTY. Jurnal EduMatSains, 1(1), 73-82.

[20] Hadi, S. (2017). Pendidikan Matematika Realistik. Jakarta: Rajawali Press.

[21] Muhassanah, N., Sujadi, I., \& Riyadi. (2014). Analisis Keterampilan Geometri dalam Memecahkan Masalah Geometri Berdasarkan Tingkat Berpikir Van Hiele. Jurnal Elektronik Pembelajaran Matematika, 2(1), 54-66.

[22] Novita, R., Prahmana, R. C. I., Fajri, N., \& Putra, M. (2018). Penyebab Kesulitan Belajar Geometri Dimensi Tiga. Jurnal Riset Pendidikan Matematika, 5(1), 18-29.

[23] Prahmana, R. C. I. (2017). Design research (Teori dan implementasinya: Suatu pengantar). Jakarta: Rajawali Press.

[24] Sulistiawati, S., Suryadi, D., \& Fatimah, S. (2015). Desain Didaktis Penalaran Matematis untuk Mengatasi Kesulitan Belajar Siswa SMP pada Luas dan Volume Limas. Kreano, Jurnal Matematika Kreatif-Inovatif, 6(2), 135-146. 
[25] Angraini, P., Prahmana, R. C. I., \& Ardhian, A. (2018). Perkembangan Siswa SMK Kelas X dalam Pembelajaran Operasi Bilangan. JPMI (Jurnal Pembelajaran Matematika Inovatif), 1(3), 289-298. 